\title{
Non-Alkaloidal Compounds from Khat (Catha edulis) Leaves
}

\author{
Tsegu Kiros \\ Department of Chemistry, College of Natural Sciences, Haramaya University, Dire Dawa, P.O.Box 138, Ethiopia. \\ Corresponding author \\ kirosorg@gmail.com
}

Manuscript received: 23 May, 2020. Revision accepted: 01 October, 2020. Published: 17 November, 2020.

\begin{abstract}
Khat belongs to the family Celastraceae, genus Catha, and species edulis. More than 200 compounds have previously been identified in Khat leaves, including: 40 alkaloids, terpenoids and sterol, flavonoids, glycosides, tannins, amino acids, vitamins and minerals. Researchers have spent their effort and time merely on study of the alkaloidal components (mainly the stimulant agents, cathinone and cathine) of Khat both qualitatively and quantitatively. The two principal Khat stimulant compounds, cathinone and cathine, by now are well established. But, on the contrary, previous studies on the non-alkaloidal constituents of the plant were limited. The objective of this work was therefore to isolate and characterize compounds from non-alkaloidal fractions of the plant's leaves. In this work, two nonalkaloidal compounds (KNA-1 and KNA-2) were isolated and characterized from the acid-EtOAc extract of fresh and oven-dried leaves of Khat (Catha edulis). From the present study, it is possible to conclude that investing more effort and time on searching additional nonalkaloidal principles from the leaves of Khat is so necessary. And further works could be done in the future to isolate extra non-alkaloidal compounds from the leaves and other parts of Khat and evaluate their biological activity.
\end{abstract}

Keywords: Khat; Catha edulis; non-alkaloid; KNA-1; KNA-2.

\section{INTRODUCTION}

Khat (Catha edulis) belongs to the family of Celastraceae and genus of Catha. It is an evergreen shrub growing to a bush or a large tree. The first scientific description and the name Catha edulis was given by the Swedish botanist Peter Forskal. The plant is known by a variety of names, including: Abyssinian tea, African salad, chat, jaad, mirra, qat, etc. The name Khat is commonly used for C. edulis (Lamina, 2010).

Khat is used commonly for mastication and its sympathomimetic actions. Consumption of Khat leaves is common in Yemen, Madagascar, Saudi Arabia and east African countries (Kenya, Ethiopia, Djibouti, Somalia, Uganda, and Tanzania). Regardless of sociodemographic characters, the number of Khat chewers in Ethiopia is increasing from time to time (Belwal and Teshome, 2011; Mathewson et al.,2013)

Beyond its deep rooted sociocultural tradition, Khat is also used to some extent as medicine. Processed leaves and roots of Khat, for example, are used to treat influenza, cough, gonorrhea, headache, asthma and other chest problems (Numan, 2003). And the leaves have been used for the treatment of depression, gastric ulcers, hunger, obesity, and tiredness (Mathewson et al., 2013; Numan, 2003; Lemessa, 2001). Moreover, Khat plays an important role in the economy of Ethiopia. It has become the source of livelihood for millions of people and is sometimes considered as a rival of coffee for income generation to Ethiopia (Ambaye, 2012).

Regarding the chemistry aspect, there are more than 200 compounds that have been identified in Khat leaves (Szendrei, 2004), including: 40 alkaloids, terpenoids and sterol, flavonoids, glycosides, tannins, amino acids, vitamins and minerals (Lamina, 2010). The chemical constitute of Khat have been studied since the late 19th century, in which an alkaloidal fraction was found in this plant by Fluckiger and Gerok and called it "katin". This was followed by the isolation of many other substances and it was not until the year 1975 that the most important component of Khat was isolated and named cathinone (S (-)-alpha-aminopropiophenone)) at the United Nations Laboratories (Dhaifalah and šntavy, 2004). The compounds reported so far from Khat can generally be classified into five main compound classes, namely, flavonoids, terpenoids and sterol, alkaloids, amino acids, and vitamins. Some of the representative compounds reported from Khat plant so far are: Dihydromyricetin (Szendrei, 2004; Al-Meshal et al., 1985; Ermias et al., 1984), Dihydromyricetin-3-Orhamnoside (Szendrei, 2004; Al-Meshal et al., 1985; Ermias et al., 1984), Kaempferol (Szendrei, 2004; AlMeshal et al., 1985; Ermias et al., 1984), Myricetin (Szendrei, 2004; Al-Meshal et al., 1985; Ermias et al., 1984; Bredholt, 2010),

Myricetin-3-O-2 D-galactoside (Szendrei, 2004; AlMeshal et al., 1985; Ermias et al., 1984), Myricetin-3-O- 
rhamnoside (Szendrei, 2004; Al-Meshal et al., 1985; Ermias et al., 1984), Quercetin (Szendrei, 2004; AlMeshal et al., 1985; Bredholt, 2010), Quercetin-3-O-2 Dgalactoside (Szendrei, 2004; Al-Meshal et al., 1985; Ermias et al., 1984), Celastrol (Bredholt, 2010; Brossi, 1990); Baxter et al., 1979), Iguesterin (Brossi, 1990; Baxter et al., 1979), Pristimerin (Bredholt, 2010; Brossi, 1990; Baxter et al., 1979),Tingenin A (Bredholt, 2010; Brossi, 1990); Baxter et al., 1979), Tingenin B ( Bredholt, 2010; Brossi, 1990; Baxter et al., 1979), Friedeline (Brossi, 1990; Baxter et al., 1979), Sitosterol (Bredholt, 2010; Brossi, 1990; Baxter et al., 1979), (+)Cathine (Brossi, 1990;Wabe and Mohammed, 2012; Feyissa and Kelly , 2008), (-)-Cathinone (Brossi, 1990; Wabe and Mohammed, 2012; Feyissa and Kelly, 2008), 3,6-Dimethyl-2,5-diphenyl pyrazine (Brossi, 1990; Wabe and Mohammed, 2012; Feyissa and Kelly, 2008), Merucathine (Brossi, 1990; Wabe and Mohammed, 2012; Feyissa and Kelly , 2008), Merucathinone (Brossi, 1990; Wabe and Mohammed, 2012; Feyissa and Kelly , 2008), Cathedulins E2- E6 (Szendrei, 2004; Dhaifalah et al., 2004; Brossi, 1990; Wabe et al., 2012; Baxter et al., 1979), Cathedulin K1 (Szendrei, 2004; Dhaifalah et al., 2004; Brossi, 1990; Wabe et al., 2012; Baxter et al., 1979), Cathedulin K2 (Szendrei, 2004; Dhaifalah et al., 2004; Brossi, 1990; Wabe et al., 2012; Baxter et al., 1979), Cathedulin K6 (Szendrei, 2004; Dhaifalah et al., 2004; Brossi, 1990; Wabe et al., 2012; Baxter et al., 1979), Cathedulin K12 (Szendrei, 2004; Dhaifalah et al., 2004; Brossi, 1990; Wabe et al., 2012; Baxter et al., 1979), Cathedulin K15 (Szendrei, 2004; Dhaifalah et al., 2004; Brossi, 1990; Wabe et al., 2012; Baxter et al., 1979), Alanine (Feyissa et al., 2008; Halbach, 1972), \pm Aminobutyric acid (Feyissa et al., 2008; Halbach, 1972), Arginine (Feyissa et al., 2008; Halbach, 1972), Asparaginic acid, (Feyissa et al., 2008; Halbach, 1972), Choline (Feyissa et al., 2008; Halbach, 1972), Glutamic acid (Feyissa et al., 2008; Halbach, 1972), Glycine (Feyissa et al., 2008; Halbach, 1972), Histidine (Feyissa et al., 2008; Halbach, 1972), Isoleucine (Feyissa et al., 2008; Halbach, 1972), Leucine (Feyissa et al., 2008; Halbach, 1972), Ornithine (Feyissa et al., 2008; Halbach, 1972), Ascorbic acid (Feyissa et al., 2008; Halbach, 1972), Niacin (Feyissa et al., 2008; Halbach, 1972), Riboflavin (Feyissa et al., 2008; Halbach, 1972) and Thiamine (Feyissa et al., 2008; Halbach, 1972).

Although the above mentioned classes of compounds were reported from the stimulant green plant, Khat, researchers have spent their effort and time merely on study of the alkaloidal components (mainly the stimulant agents, cathinone and cathine) both qualitatively and quantitatively. As a result, the two principal Khat stimulant compounds, cathinnoe and cathine, are now well established. But, on the contrary, previous studies on the non-alkaloidal constituents of the plant were limited. It therefore became apparent that it is necessary to undertake a phytochemical study in order to give an attention to the chemical constituents of Khat other than the most studied alkaloidal one. The objective of this work was therefore to isolate and characterize compounds from non-alkaloidal fractions of the plant's leaf.

\section{MATERIALS AND METHODS}

\section{Plant Material}

Khat plant $(C$. edulis) was collected from the province known as Sebeta, $20 \mathrm{~km}$ far from the capital city, Addis Ababa, Ethiopia. Two types of leaves are easily recognized in Khat plant; the chewable and "nonchewable". The chewable parts are usually shiny tender greenish young leaves found on the tip of a branch. The "non-chewable" leaves known locally as "Geraba" are found on the lower part of a branch and are much older, harder and deep green in color. The fresh chewable leaves were used for immediate extraction and the "nonchewable" leaves were oven-dried $\left(50^{\circ} \mathrm{C}\right)$.

\section{Chemicals, Apparatuses and Instruments}

Chemicals such as visualizing agent (vanillin/ $\mathrm{MeOH} /$ conc. $\left.\mathrm{H}_{2} \mathrm{SO}_{4}\right), \mathrm{HCl}(37 \%), \mathrm{EtOAc}, \mathrm{MeOH}$ and acetone were used. Besides, apparatuses and instruments including TLC plate (pre-coated aluminum sheet silica gel 60 F254), chamber, capillary tube, shaker 3020, NMR (BRUKER AVANCE $400 \mathrm{MHz}$ spectrometer), vacuum oven (SV40), rotavapor (R-114), sonicator (3210 BRANSON), UV lamp (CC-8), UV/Vis spectrophotometer (T60) and digital melting point (Electrothermal IA 9200) were employed in the present study.

\section{Isolation of non-alkaloidal compounds from khat leaves}

The fresh chewable Khat leaves $(60 \mathrm{~g})$ were extracted with $0.1 \mathrm{~N} \mathrm{HCl}(300 \mathrm{~mL})$ and filtered by suction filtration. The filtrate was extracted with EtOAc (100 $\mathrm{mL}$ ) and separated the organic phase by separatory funnel, concentrated by rotavapor affording $140 \mathrm{mg}$.

The plant extract $(140 \mathrm{mg})$ was dissolved in $\mathrm{MeOH}$ $(10 \mathrm{~mL})$ and adsorbed on $1 \mathrm{~g}$ silica gel $(230$ - 400 mesh size). The adsorbed sample was chromatographed by applying on top of column chromatography packed with silica gel (12 g). Elution was carried out using EtOAc/ Acetone with increasing polarity and five fractions were collected (Table 1).

Table 1. Collected fractions of acid-EtOAc extract of chewable leaves.

\begin{tabular}{clll}
\hline $\begin{array}{c}\text { Fraction } \\
\text { No. }\end{array}$ & Solvent system & $\begin{array}{l}\text { Volume } \\
(\mathbf{m L})\end{array}$ & $\begin{array}{l}\text { Amount } \\
(\mathbf{m g})\end{array}$ \\
\hline 1 & EtOAc $(100 \%)$ & 5 & 4 \\
2 & “ & 10 & 15 \\
3 & " & 20 & 15 \\
4 & EtOAc/ Acetone (2:1) & “ & 20 \\
5 & “ & “ & 14 \\
\hline
\end{tabular}


As shown from the TLC profile (Figure 1) of the above fractions (Table 1), fraction 4 (KNA-1) was seen as a better spot; it was then concentrated $(20 \mathrm{mg})$ and obtained as yellow solid; $\mathrm{mp} 190-192^{\circ} \mathrm{C}$ (literature value $192-195^{\circ} \mathrm{C}$, Dictionary of Natural Product); $\mathrm{R}_{\mathrm{f}}$ in TLC: $0.6(\mathrm{EtOAc} / \mathrm{MeOH} / \mathrm{AcOH}$; 4.5: 0.5: 1) sprayed with vanillin/ $\mathrm{MeOH} /$ con. $\mathrm{H}_{2} \mathrm{SO}_{4}$ (0.3: 95: 5); $\mathrm{UV}(\mathrm{MeOH})$ $\lambda \max 293 \mathrm{~nm} .{ }^{1} \mathrm{H}$ NMR $(400 \mathrm{MHz}, \mathrm{MeOD}): \delta \mathrm{H} 5.01$ $(1 \mathrm{H}$, br s, H-2), $4.56(1 \mathrm{H}, \mathrm{d}, \mathrm{H}-3), 5.93(1 \mathrm{H}$, br s, H-6), $5.92\left(1 \mathrm{H}\right.$, br s, H-8), $6.54\left(2 \mathrm{H}, \mathrm{s}, \mathrm{H}-2^{\prime}, 6^{\prime}\right), 4.10(1 \mathrm{H}, \mathrm{br}$ s, H-1"), 3.61 (1H, br s, H-2"), 3.70 (1H, d, H-3"), 3.33 (1H, br s, H-4"), 4.28 (1H, m, H-5"), 1.22 (3H, d, H-6"). ${ }^{13} \mathrm{C}$ NMR (400MHz, MeOD): $\delta \mathrm{C} 82.68(\mathrm{C}-2), 77.06(\mathrm{C}-$ 3), 95.99 (C-6), 94.89 (C-8), 106.25 (C-2', 6'), 100.69 (C-1”), 70.36 (C-2”), 70.74 (C-3"), 72.43 (C-4”), 69.11 (C-5"), 16.51 (C-6"). DEPT-135: $8 \mathrm{C}$ (194.53 (C-4), 164.06 (C-5), 167.17 (C-7), 162.65 (C-9), 101.05 (C10), 126.99 (C-1'), 145.63 (C-3', 5'), 133.68 (C-4').

Same extraction method as above was applied for the vacuum oven dried powder "non-chewable" (25 g) Khat leaves and afforded $150 \mathrm{mg}$ of EtOAc extract for the acid extract. The plant extract $(150 \mathrm{mg})$ was dissolved in $\mathrm{MeOH}(10 \mathrm{~mL})$ and adsorbed on $1 \mathrm{~g}$ silica gel. The adsorbed sample was chromatographed by applying on top of a column chromatography packed with silica gel $(13 \mathrm{~g})$ and eluted using EtOAc/ $\mathrm{MeOH}$ with increasing polarity. Six fractions were collected (Table 2).

Table 2. Collected fractions of acid-EtOAc extract of "non-chewable" leaves.

\begin{tabular}{clll}
\hline $\begin{array}{c}\text { Fraction } \\
\text { No. }\end{array}$ & Solvent system & $\begin{array}{l}\text { Volume } \\
(\mathbf{m L})\end{array}$ & $\begin{array}{l}\text { Amount } \\
(\mathbf{m g})\end{array}$ \\
\hline 1 & EtOAc $(100 \%)$ & 10 & 10 \\
2 & “ & 15 & 15 \\
3 & “ & 20 & 40 \\
4 & “ & 10 & 20 \\
5 & “ & 30 & 15 \\
6 & EtOAc/ $\mathrm{MeOH}(4: 1)$ & 25 & 20 \\
\hline
\end{tabular}

As shown from the TLC profile (Figure 2) of the above fractions (Table 2), different spots were observed in the chromatogram after it was subjected to UV lamp at $254 \mathrm{~nm}$. Among the fractions, fraction 1(KNA-2) was concentrated $(10 \mathrm{mg})$ and obtained as an orange solid; mp $165-168^{\circ} \mathrm{C}$; UV (MeOH) $\lambda \max 292 \mathrm{~nm} ; \mathrm{R}_{\mathrm{f}}$ in TLC: 0.8 (EtOAc/ $\mathrm{MeOH} / \mathrm{AcOH}$; 4.5: 0.5: 0.1) sprayed with vanillin/ $\mathrm{MeOH} /$ con. $\mathrm{H}_{2} \mathrm{SO}_{4}$ (0.3: 95: 5). ${ }^{1} \mathrm{H}$ NMR (400 $\mathrm{MHz}, \mathrm{MeOD}): \delta \mathrm{H} 4.86(1 \mathrm{H}, \mathrm{d}, \mathrm{H}-2), 4.49(1 \mathrm{H}, \mathrm{d}, \mathrm{H}-3)$, $5.90(1 \mathrm{H}$, br s, H-6), $5.93(1 \mathrm{H}$, br s, H-8), $6.54(2 \mathrm{H}, \mathrm{br} \mathrm{s}$, H-2', 6'). ${ }^{13} \mathrm{C}$ NMR (400 MHz, MeOD): $\delta \mathrm{C} 83.90(\mathrm{C}-2)$, 72.28 (C-3), 94.85 (C-6), 95.87 (C-8), 106.61 (C-2', 6'). DEPT-135: $\delta \mathrm{C} 196.93$ (C-4), 163.91 (C-5), 167.30 (C7), 163.05 (C-9), 100.41 (C-10), 133.51 (C-1'), 145.47, 145.47 (C-3', 5'), 127.66 (C-4').

\section{RESULTS AND DISCUSSION}

Two types of leaves are easily recognized in Khat plant; the chewable and "non-chewable". The chewable parts are usually shiny tender greenish young leaves found on the tip of a branch. The "non-chewable" leaves known locally as "Geraba" are found on the lower part of a branch and are much older, harder and deep green in color. In the present work, these leaves were analyzed to isolate non-alkaloidal components.

In order to isolate non-alkaloidal components, the Khat leaves were first extracted with $0.1 \mathrm{~N} \mathrm{HCl}$, filtered, and extracted with EtOAc. This EtOAc extract was fractionated to isolate the non-alkaloidal compounds as described in the experimental section.

\section{Characterization of Two Khat Non-Alkaloidal (KNA-1 and KNA-2) Compounds}

The EtOAc extract of fresh chewable Khat leaves (see section 2.3) was chromatographed by applying on top of column chromatography packed with silica gel. Elution was carried out using EtOAc/ Acetone with increasing polarity and five fractions were collected (Table 1).

Similarly, the EtOAc extract of vacuum oven dried "non-chewable" Khat leaves (see section 2.3) was chromatographed on column silica gel using EtOAc/ $\mathrm{MeOH}$ with increasing polarity and six fractions were collected (Table 2).

\section{Thin - Layer Chromatographic (TLC) Analysis}

Using EtOAc/ $\mathrm{MeOH} / \mathrm{AcOH}$ (4.5: 0.5: 0.1) as developing solvent, the fractions (Table 1) were spotted and chromatogramed on a TLC plate. The TLC plate was then sprayed with vanillin/ $\mathrm{MeOH} /$ conc. $\mathrm{H}_{2} \mathrm{SO} 4$ (1: 95: 5). As shown from the TLC profile (Figure 1), fraction 4 (KNA-1) was seen as a better spot, concentrated $(20 \mathrm{mg})$ and characterized.

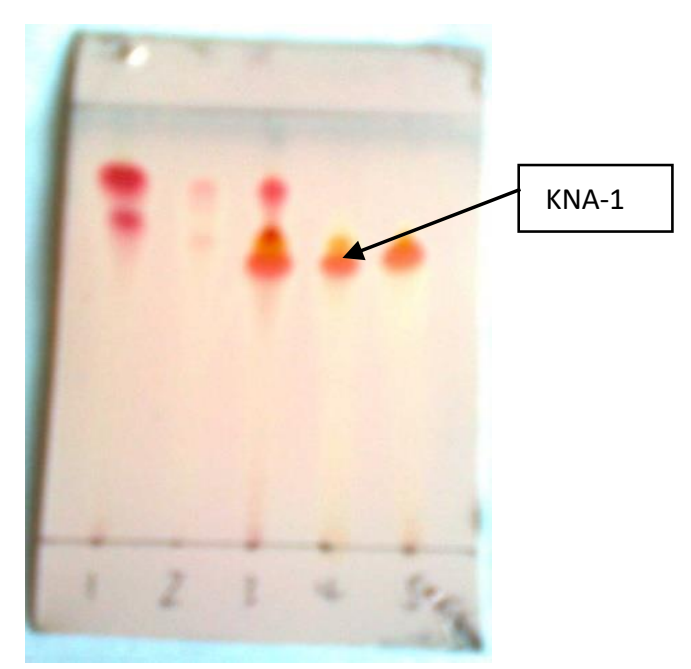

Figure 1. TLC profile of fractions of acid-EtOAc extract of chewable leaves. 
The same solvent system with same ratio and spraying reagent as above were applied here for the fractions stated in Table 2. As shown from the TLC profile (Figure 2), fraction 1(KNA-2) was observed as a better spot.

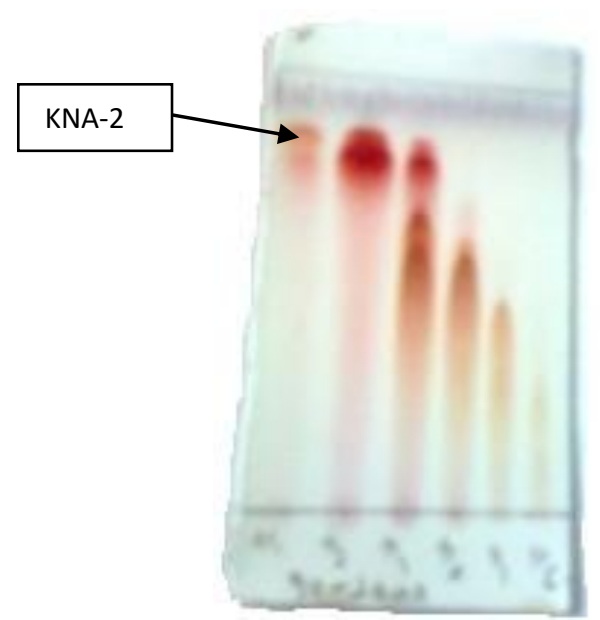

Figure 2. TLC profile of fractions of acid-EtOAc extract of "nonchewable" leaves.

Characterization of compound KNA-1: It was obtained as yellow solid; mp 190- 192 oC (literature value $192-195^{\circ} \mathrm{C}$, Dictionary of Natural Product); $\mathrm{R}_{\mathrm{f}}$ in TLC: 0.6 (EtOAc/ MeOH/ AcOH; 4.5: 0.5: 1) sprayed with vanillin/ $\mathrm{MeOH} /$ con. H2SO4 (0.3: 95: 5); UV $(\mathrm{MeOH}) \lambda \max 293 \mathrm{~nm}$. The ${ }^{1} \mathrm{H}$ NMR (400 MHz, MeOD) spectrum showed a doublet at $\delta 4.56(1 \mathrm{H}, \mathrm{d}, \mathrm{J}=$ $10.8 \mathrm{~Hz}, \mathrm{H}-3)$ and a broad singlet at $\delta 5.01(\mathrm{H}-2)$ which were due to the two protons at C-3 and C-2 of flavanol skeleton, respectively. The two broad singlets observed at $\delta 5.92(\mathrm{H}-6)$ and $5.93(\mathrm{H}-8)$ were due to the aromatic protons of A-ring of a flavonoid skeleton at C-6 and C8 , respectively. The broad singlet at $\delta 6.54$ (H-2' \& -6') integrated to two protons was due to the overlapping of signals for the symmetric aromatic protons of B-ring at C-2' and C-6' of flavonoid skeleton. The oxymethinic proton signals between $\delta \mathrm{H} 3.33$ - 4.28, together with the methyl proton signal at $\delta \mathrm{H} 1.22(3 \mathrm{H}, \mathrm{d}, \mathrm{J}=6.4 \mathrm{~Hz}, \mathrm{H}-$ 6 "), and the oxymethinic carbon signals between $\delta \mathrm{C}$ 69.11-100.69, including the methyl carbon signal at $\delta \mathrm{C}$ 16.51 indicated that a rhamnoside sugar was attached. The doublet signal at $\delta \mathrm{H} 1.22(3 \mathrm{H}, \mathrm{d}, \mathrm{J}=6.4 \mathrm{~Hz}, \mathrm{H}-6$ ") was a characteristic for the rhamnoside moiety. The three broad singlets at $\delta \mathrm{H} 3.33$ (H-4”), 3.61 (H-2"), and 4.10 (H-1") were due to the rhamnoside protons positioned at C-4", C-2", and C-1", respectively. The methine proton at $\mathrm{C}-3$ " of the sugar moiety was observed as a doublet at $\delta \mathrm{H} 3.70(1 \mathrm{H}, \mathrm{d}, \mathrm{J}=9.6 \mathrm{~Hz}, \mathrm{H}-$ 3 "), and the muliplet signal at $\delta \mathrm{H} 4.28$ (H-5") was characteristic signal for the rhamnoside proton attached at C-5" which contains a substituted methyl group. The ${ }^{13} \mathrm{C}$ NMR spectrum showed the presence of nineteen signals attributed to twenty-one different carbons. The spectral region between $\delta \mathrm{C}$ 94.89-167.17 was characteristic of aromatic carbons of A- and B-rings of flavonoid skeleton with the exception of the signal at $\delta \mathrm{C}$ 100.69 (C-1") which was due to the anomeric carbon of the rhamnoside moiety. The remaining carbon atoms of the sugar moiety were observed in the spectral region at $\delta \mathrm{C}$ 69.11-72.43 including the methyl carbon appeared at

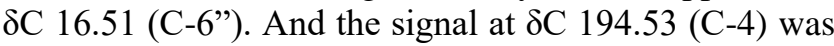
characteristic of carbonyl carbon of ketone functional groups (Table 3). Signals at $\delta \mathrm{C} 77.06$ (C-3) and 82.68 (C-2) were due to $\alpha, \beta$ carbons of $\mathrm{C}$-ring (pyranone), and were compatible with a dihydroflavanol structure which were comparable with a literature value [18] Medeiros AAN, Medeiros FA, Queiroz TM, Tavares JF, Silva MS, Medeiros IA (2010). From the DEPT-135 spectrum, there were nine quaternary carbons one to a carbonyl carbon at $\delta \mathrm{C} 194.53$ (C-4), and eight to aromatic carbons of A- and B-rings. The eleven signals appeared in the positive direction were due to the methine $(-\mathrm{CH})$ carbons containing two symmetric carbons overlapped with each other at $\delta \mathrm{C} 106.25$ (C-2', -6'), and a methyl carbon at $\delta \mathrm{C} 16.51$ (C-6"). The above 1D NMR data is summarized as follows (Table 3 ).

Table 3. ${ }^{1} \mathrm{H},{ }^{13} \mathrm{C}$ and DEPT NMR data ( $\delta$ ppm) of compound KNA-1.

\begin{tabular}{|c|c|c|c|c|c|}
\hline \multicolumn{4}{|c|}{ Isolated compound (KNA-1) } & \multicolumn{2}{|c|}{$\begin{array}{l}\text { Literature value } \\
\text { (Medeiros } \text { et al., } \\
\text { 2010) } \\
(2,3 \text { - } \\
\text { dihydromyricetin- } \\
\text { 3-O-rhamnoside) }\end{array}$} \\
\hline $\mathrm{C} / \mathrm{H}$ & ${ }^{1} \mathrm{H}$ & ${ }^{13} \mathrm{C}$ & DEPT-135 & ${ }^{1} \mathrm{H}$ & ${ }^{13} \mathrm{C}$ \\
\hline 2 & 5.01 , br s & 82.68 & $-\mathrm{CH}-$ & $4.86, \mathrm{~d}$ & 83.20 \\
\hline 3 & $4.56, \mathrm{~d}$ & 77.06 & CH-O- & $4.61, \mathrm{~d}$ & 76.80 \\
\hline 4 & & 194.53 & $\mathrm{C}=\mathrm{O}(\mathrm{Q})$ & - & 194.30 \\
\hline 5 & & 164.06 & Q & - & 165.40 \\
\hline 6 & 5.93 , br s & 95.99 & $=\mathrm{CH}$ & $5.90, \mathrm{~d}$ & 96.00 \\
\hline 7 & & 167.17 & Q & - & 166.90 \\
\hline 8 & 5.92 , br s & 94.89 & $=\mathrm{CH}$ & $5.87, \mathrm{~d}$ & 95.00 \\
\hline 9 & & 162.65 & Q & - & 162.10 \\
\hline 10 & & 101.05 & Q & - & 101.00 \\
\hline 1 ' & & 126.99 & Q & - & 126.80 \\
\hline $2^{\prime}$ & $6.54, \mathrm{~s}$ & 106.25 & $=\mathrm{CH}$ & $6.50, \mathrm{~s}$ & 108.00 \\
\hline $3^{\prime}$ & & 145.63 & Q & - & 145.80 \\
\hline 4 & & 133.68 & Q & - & 135.20 \\
\hline 5 & & 145.63 & $\mathrm{Q}$ & - & 145.80 \\
\hline $6^{\prime}$ & $6.54, \mathrm{~s}$ & 106.25 & $=\mathrm{CH}$ & $6.50, \mathrm{~s}$ & 108.00 \\
\hline $1 "$ & 4.10 , br s & 100.69 & CH-O- & $4.07, \mathrm{~s}$ & 100.00 \\
\hline $2 "$ & 3.61, br s & 70.36 & $\mathrm{CH}-\mathrm{OH}$ & 3.36 , br s & 70.10 \\
\hline $3 "$ & $3.70, \mathrm{~d}$ & 70.74 & $\mathrm{CH}-\mathrm{OH}$ & $3.41, \mathrm{dd}$ & 70.40 \\
\hline $4 "$ & 3.33 , br s & 72.43 & $\mathrm{CH}-\mathrm{OH}$ & $3.20, \mathrm{dd}$ & 71.60 \\
\hline $5 "$ & $4.28, \mathrm{~m}$ & 69.11 & CH-O- & $3.88, \mathrm{~m}$ & 68.90 \\
\hline $6 "$ & $1.22, \mathrm{~d}$ & 16.51 & $-\mathrm{CH}_{3}$ & $0.92, \mathrm{~d}$ & 17.60 \\
\hline
\end{tabular}

The extensive 2D NMR experiments involving ${ }^{1} \mathrm{H}-$ ${ }^{1} \mathrm{H}$ COSY, HMQC, HMBC spectra supported the 1D NMR data above for the proposed structure of KNA-1. 
The COSY spectrum of KNA-1 is used to determine $1 \mathrm{H}$ $1 \mathrm{H}$ correlations. As stated in Table 4, except the protons at $\delta \mathrm{H} 5.93$ (H-6), 5.92 (H-8), and 6.54 (H-2', 6') which showed a correlation only with themselves, all the rest protons of the rhamnoside moiety and the pyranone $(\mathrm{C}$ ring) made a correlation more than one bond. The two protons at $\delta \mathrm{H} 5.01(\mathrm{H}-2)$ and $4.56(\mathrm{H}-3)$ are coupled through vicinal (3J) coupling with each other. The anomeric proton of the rhamnoside moiety at $\delta \mathrm{H} 4.10$

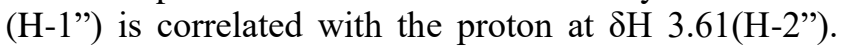
The methyl group of the rhamnoside at $\delta \mathrm{H} 1.22$ (Me-6") showed a correlation with a proton at $\delta \mathrm{H} 4.28$ (H-5").
The HMQC spectrum of KNA-1 is utilized to determine direct ${ }^{1} \mathrm{H}-{ }^{13} \mathrm{C}$ correlations (Table 4), while the $\mathrm{HMBC}$ correlations described the long range $1 \mathrm{H}-13 \mathrm{C}$ connectivities. The $\mathrm{H}-2$ proton of the C-ring at $\delta \mathrm{H} 5.01$ displayed HMBC correlations with C-2', 6' ( $\delta \mathrm{C} 106.25)$ and $\mathrm{C}-1$ ' ( $\delta \mathrm{C} 126.99)$ of the B-ring. The $\mathrm{H}-3$ proton at $\delta \mathrm{H} 4.56$ showed a correlation with $\mathrm{C}-1 "$ " ( $\delta \mathrm{C} 100.69)$, which indicated the rhamnoside moiety is attached at $\mathrm{C}$ 3 position. The symmetric protons of the B-ring at $\delta \mathrm{H}$ 6.54 (H-2', 6') showed a correlation with $\mathrm{C}-2$ of the pyranone (C-ring).

Table 4. COSY, HMQC and HMBC data of compound KNA-1.

\begin{tabular}{|c|c|c|c|}
\hline Proton No. & COSY & HMQC & HMBC \\
\hline 2 & $\mathrm{H}-2 \longleftrightarrow \mathrm{H}-3$ & $\mathrm{H}-2 \leftrightarrow \mathrm{C}-2$ & $\mathrm{H}-2 \leftrightarrow \mathrm{C}-1^{\prime}, \mathrm{C}-2, \mathrm{C}-6$ \\
\hline 3 & $\mathrm{H}-3 \longleftrightarrow \mathrm{H}-2$ & $\mathrm{H}-3 \leftrightarrow \mathrm{C}-3$ & $\mathrm{H}-3 \leftrightarrow \mathrm{C}-1 "$ \\
\hline 6 & & $\mathrm{H}-6 \leftrightarrow \mathrm{C}-6$ & $\mathrm{H}-6 \leftrightarrow \mathrm{C}-8, \mathrm{C}-10$ \\
\hline 8 & & $\mathrm{H}-8 \leftrightarrow \mathrm{C}-8$ & $\mathrm{H}-8 \leftrightarrow \mathrm{C}-6, \mathrm{C}-9$ \\
\hline $2^{\prime}$ & & $\mathrm{H}-2^{\prime} \leftrightarrow \mathrm{C}-2^{\prime}$ & $\mathrm{H}-2 \longleftrightarrow \mathrm{C}-2$ \\
\hline $6^{\prime}$ & & $\mathrm{H}-6 \stackrel{ }{\prime} \leftrightarrow \mathrm{C}-6$ & $\mathrm{H}-6 \leftrightarrow \mathrm{C}-2$ \\
\hline $1 "$ & $\mathrm{H}-1 " \longleftrightarrow \mathrm{H}-2 "$ & $\mathrm{H}-1 " \stackrel{\mathrm{C}-1 "}{\leftrightarrow}$ & 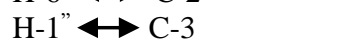 \\
\hline $2 "$ & $\mathrm{H}-2 " \longleftrightarrow \mathrm{H}-1 ", \mathrm{H}-3 "$ & $\mathrm{H}-2 " \longleftrightarrow \mathrm{C}-2 "$ & 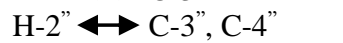 \\
\hline $3 "$ & $\mathrm{H}-3 " \longleftrightarrow \mathrm{H}-2 ", \mathrm{H}-4 "$ & $\mathrm{H}-3 " \leftrightarrow \mathrm{C}-3 "$ & $\mathrm{H}-3 " \leftrightarrow \mathrm{C}-2 ", \mathrm{C}-4 "$ \\
\hline $4 "$ & $\mathrm{H}-4 " \longleftrightarrow \mathrm{H}-3 ", \mathrm{H}-5 "$ & 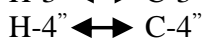 & $\mathrm{H}-4 " \leftrightarrow \mathrm{C}-2 ", \mathrm{C}-6 "$ \\
\hline $5 "$ & $\mathrm{H}-5 " \longleftrightarrow \mathrm{H}-4 ", \mathrm{H}-6 "$ & 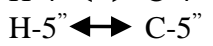 & $\mathrm{H}-5 " \leftrightarrow \mathrm{C}-2$ ", C-6" \\
\hline $6 "$ & $\mathrm{H}-6 " \longleftrightarrow \mathrm{H}-5 "$ & $\mathrm{H}-6 " \leftrightarrow \mathrm{C}-6 "$ & $\mathrm{H}-6 " \leftrightarrow \mathrm{C}-2$ ", C-5" \\
\hline
\end{tabular}

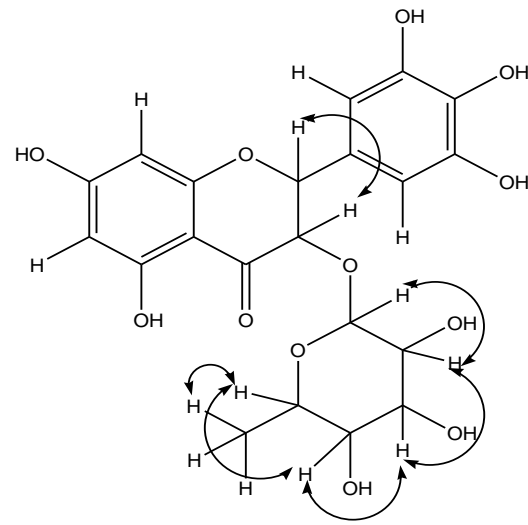

COSY correlation

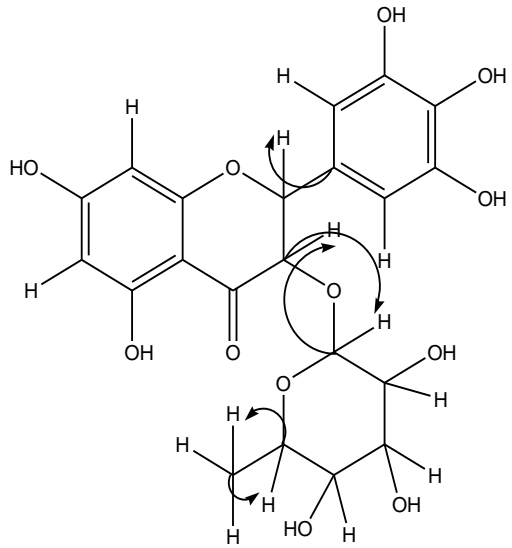

Selected HMBC correlation
The structure of KNA-1 was deduced as 2, 3dihydromyricetin-3-O-rhamnoside (Figure 3) in comparison of the data with the literature and then confirmed by the 2D NMR data. This compound belongs to a group of secondary metabolites called flavonoids.

Characterization of compound KNA-2: It was obtained as an orange solid; mp 165-168 ${ }^{\circ} \mathrm{C}$; UV $(\mathrm{MeOH}) \lambda \max 292 \mathrm{~nm}$; $\mathrm{R}_{\mathrm{f}}$ in TLC: 0.8 (EtOAc/ MeOH/ $\mathrm{AcOH}$; 4.5: 0.5: 0.1) sprayed with vanillin/ $\mathrm{MeOH} / \mathrm{con}$. H2SO4; 0.3: 95: 5.

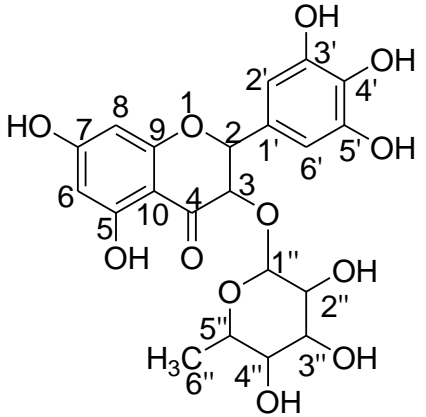

Figure 3. Suggested chemical structure of compound KNA-1 
The ${ }^{1} \mathrm{H},{ }^{13} \mathrm{C}$, and DEPT NMR spectral values of KNA-2 are tabulated and compared with literature value (Jr et al., 2009) as follows (Table 5).

Table 5. ${ }^{1} \mathrm{H},{ }^{13} \mathrm{C}$ and DEPT NMR data ( $\left.\delta \mathrm{ppm}\right)$ of compound KNA-2.

\begin{tabular}{llllll}
\hline \multicolumn{3}{l}{ Isolated compound (KNA-2) } & & \multicolumn{3}{l}{$\begin{array}{l}\text { Literature value } \\
\text { (Jr } \text { et al., 2009) } \\
(\mathbf{2}, \mathbf{3}- \\
\text { dihydromyricetin) }\end{array}$} \\
\hline $\mathrm{C} / \mathrm{H}$ & ${ }^{1} \mathrm{H}$ & ${ }^{13} \mathrm{C}$ & $\mathrm{DEPT}-135$ & ${ }^{1} \mathrm{H}$ & ${ }^{13} \mathrm{C}$ \\
2 & $4.86, \mathrm{~d}$ & 83.90 & $-\mathrm{CH}-$ & $4.96, \mathrm{~d}$ & 84.40 \\
3 & $4.49, \mathrm{~d}$ & 72.28 & $-\mathrm{CH}-\mathrm{OH}$ & $4.57, \mathrm{~d}$ & 72.90 \\
4 & - & 196.93 & $\mathrm{C}=\mathrm{O}(\mathrm{Q})$ & - & 197.9 \\
5 & - & 163.91 & $\mathrm{Q}$ & - & 164.00 \\
6 & 5.90, br s & 94.85 & $=\mathrm{CH}$ & $5.94, \mathrm{~s}$ & 95.70 \\
7 & - & 167.30 & $\mathrm{Q}$ & - & 167.60 \\
8 & 5.93, br s & 95.87 & $=\mathrm{CH}$ & $5.98, \mathrm{~s}$ & 96.80 \\
9 & - & 163.05 & $\mathrm{Q}$ & - & 164.8 \\
10 & - & 100.41 & $\mathrm{Q}$ & - & 101.40 \\
1 & - & 133.51 & $\mathrm{Q}$ & - & 134.00 \\
$2^{\prime}$ & 6.54, br s & 106.61 & $=\mathrm{CH}$ & $6.62, \mathrm{~s}$ & 107.90 \\
3 & - & 145.47 & $\mathrm{Q}$ & - & 146.10 \\
4 & - & 127.66 & $\mathrm{Q}$ & - & 128.90 \\
5 & - & 145.47 & $\mathrm{Q}$ & - & 146.10 \\
6 & 6.54, br s & 106.61 & $=\mathrm{CH}$ & $6.62, \mathrm{~s}$ & 107.90 \\
\hline
\end{tabular}

Depending on the above NMR data along with the literature value, the structure of KNA-2 was suggested as 2, 3-dihydromyricetin (Figure 4) which belongs to a group of secondary metabolites called aglycones flavonoid. This compound was first reported in Khat leaves in 1980 (Szendrei, 2004). It was also isolated from a plant known as Elderberry (sambucus nigra L.) in 2009 and has biological activities as anti-virus and antiinfluenza (Jr et al., 2009).<smiles>O=C1c2c(O)cc(O)cc2OC(c2cc(O)c(O)c(O)c2)C1O</smiles>

Figure 4. Suggested chemical structure of compound KNA-2

\section{CONCLUSION}

From the present study, it is possible to conclude that investing more effort and time on searching additional non-alkaloidal principles from the leaf part of Khat is so necessary. And further works could be done in the future to isolate extra non-alkaloidal compounds from the leaf and other parts of Khat and evaluate their biological activity.
Acknowledgements: The author would like to thank the Ethiopian Ministry of Education and Addis Ababa University for their financial support.

Conflict of interest: The author declares that there are no conflicts of interest concerning the publication of this article.

\section{REFERENCES}

Al-Meshal IA, Hifnawy, MS, Asir M (1985) Myricetin, dihydromyricetin, and quercetin glycosides from Catha edulis. J. Nat. Prod. 49(1): 172.

Ambaye GG (2012) Production and consumption trends of khat in ethiopia: a big business or a big worry. Advances in Agriculture, Sciences and Engineering Research 2(10): 414 427.

Baxter RL, Crombie L, Simmonds DJ, Whiting DA (1979) Alkaloids of Catha edulis (Khat). Part I, isolation and characterization of eleven new alkaloids with sesquiterpene cores (cathedulins); identification of the quinone methide root pigments. J.C.S. Perkin I 2965 - 2971.

Baxter RL, Crombie WML, Crombie L, Simmonds DJ, Whiting DA (1979) Alkaloids of Catha edulis. Part 4, structures of cathedulins E3, E4, E5, E6, and K12. Novel sesquiterpene alkaloids with mono- and bismacrolide bridges. J.C.S. Perkin I 2982 - 2989.

Belwal R, Teshome H (2011) khat exports and the ethiopian economy: opportunities, dilemmas and constraints. African Journal of Business Management 5(9): 3635 - 3648.

Bredholt T (2010) Delineating cellular and molecular mechanisms of toxicity of an extract of Khat (Catha edulis Forsk.) in leukemia and normal peripheral blood cells. [Dissertation].

Brossi A (1990) The alkaloids: chemistry and pharmacology. Academic Press, Inc.

Dhaifalah I, `šntavy J (2004) Khat habit and its health effect, a natural amphetamine. Biomed. Papers 148(1): 11- 15.

Ermias D, Sebsebe D, Kalman S, Brenneisen R, Peter K, Amha M, Zein AZ (1984) International symposium on Khat: chemical and ethnopharmacological aspects of Khat. Proceedings, Addis Ababa University, Addis Ababa, 1984. [Ethiopia].

Feyissa AM, Kelly PJ (2008) A review of the neuropharmacological properties of Khat. Progress in NeuroPsychopharmacology and Biological Psychiatry 32: 11471166.

Halbach H (1972) Medical aspects of the chewing of Khat leaves. Bull. Org. mond. Sante 47: 21- 29.

Jr BR, Fink RC, McMichael MD, Li D, Alberte RS. (2009) Elderberry flavonoids bind to and prevent h1n1 infection in vitro. Phytochemistry 70: $1255-1261$.

Lamina S (2010) Khat (Catha edulis): the herb with officio-legal, sociocultural and economic uncertainty. S. Afr. J. Sci. 106(3/4): 1- 4 .

Lemessa D (2001) Khat (Catha edulis): botany, distribution, cultivation, usage and economics in Ethiopia. UNEmergencies Unit for Ethiopia, 1- 14.

Mathewson H, James K, Schifano F, Sumnall H, Wing A, Anderson D (2013) Khat: a review of its potential harms to 
the individual and communities in the UK. Advisory Council on the Misuse of Drugs. 1- 96.

Medeiros AAN, Medeiros FA, Queiroz TM, Tavares JF, Silva MS, Medeiros IA (2010) Effects of extract, fractions and 2,3dihydromyricetin-3-O- $\alpha$-L-rhamnoside from Pradosia huberi (Ducke) Ducke on rat isolated mesenteric arteries. Brazilian Journal of Pharmacognosy 20(4): 542 - 548.

Numan NMD (2003) The green leaf concept of khat chewing in yemen: social, cultural, psychological and medical aspects for khat use. [Dissertation].
Szendrei K (2004) The chemistry of Khat. UNODC-Bulletin on Narcotics 5- 35.

Wabe NT, Mohammed MA (2012) What science says about Khat (Catha edulis Forsk)? Overview of chemistry, toxicology and pharmacology. Journal of Experimental and Integrative Medicine 2(1): 29 - 37. 
Figure S1. UV (MeOH) spectra of KNA-1 and KNA-2.

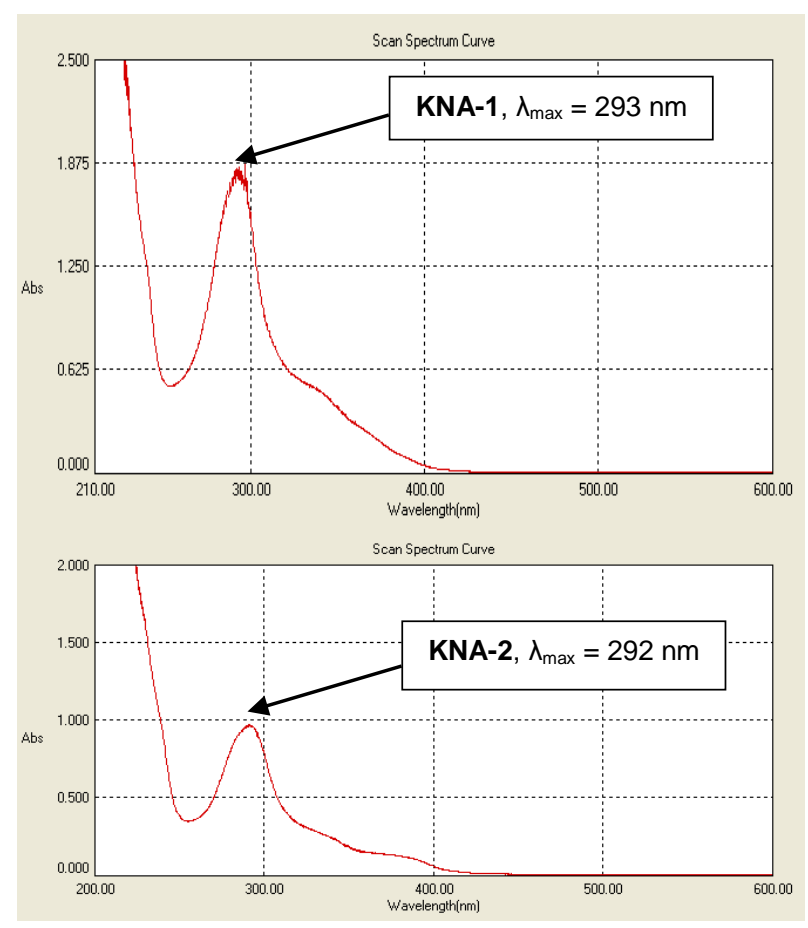

Figure S2. ${ }^{1} \mathrm{H}$ NMR (400 MHz, MeOD) spectrum of KNA-1.

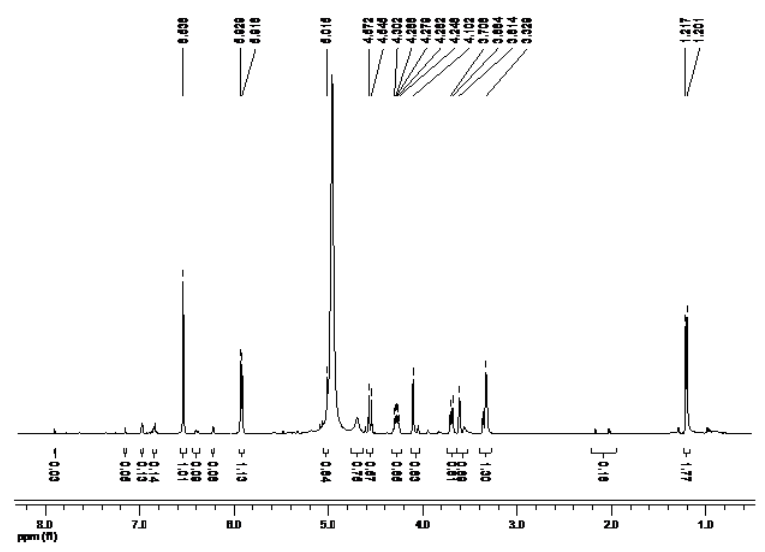

Figure S3. ${ }^{13} \mathrm{C}$ NMR (400 MHz, MeOD) spectrum of KNA-1.

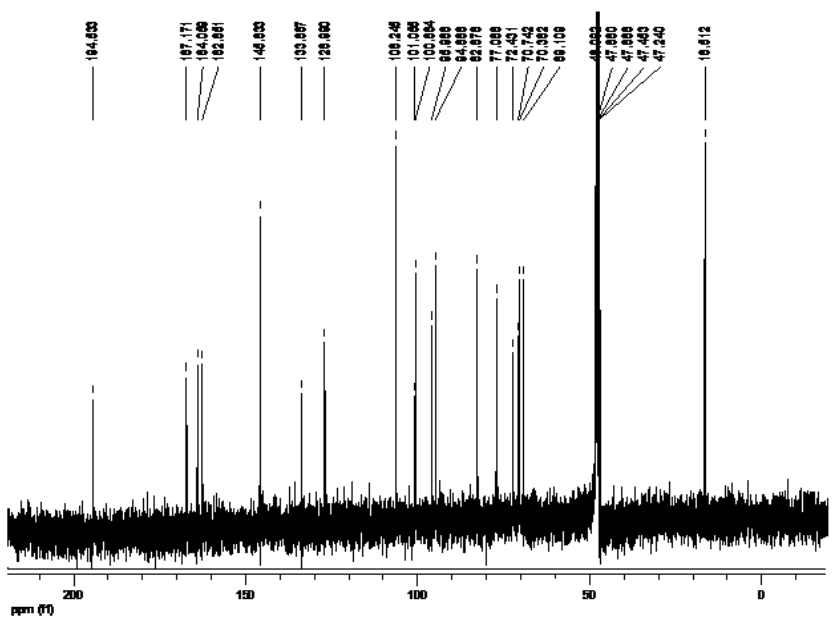

Figure S4. DEPT-135 spectrum of KNA-1.

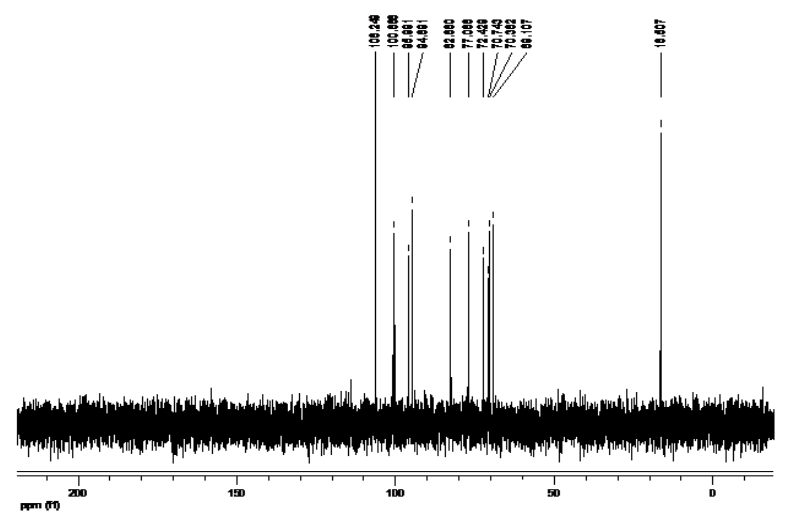

Figure S5. COSY spectrum of KNA-1.

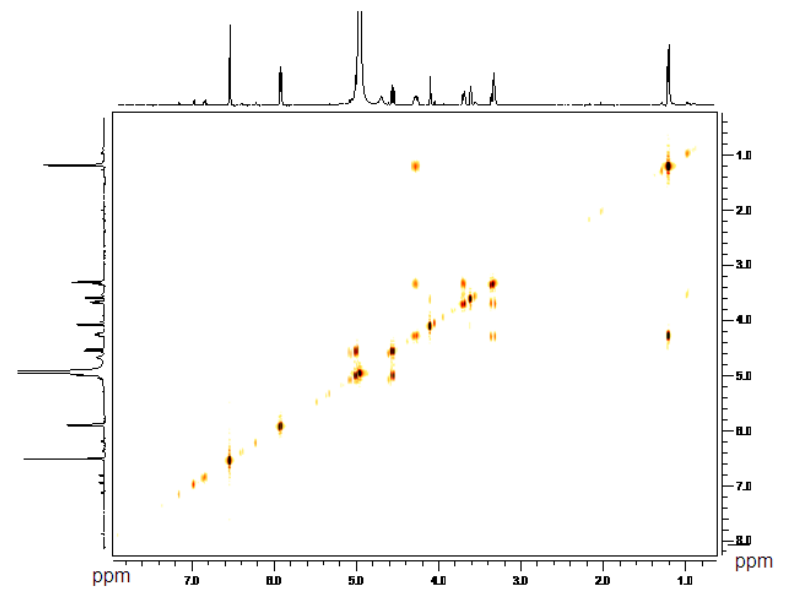

Figure S6. HMQC spectrum of KNA-1.

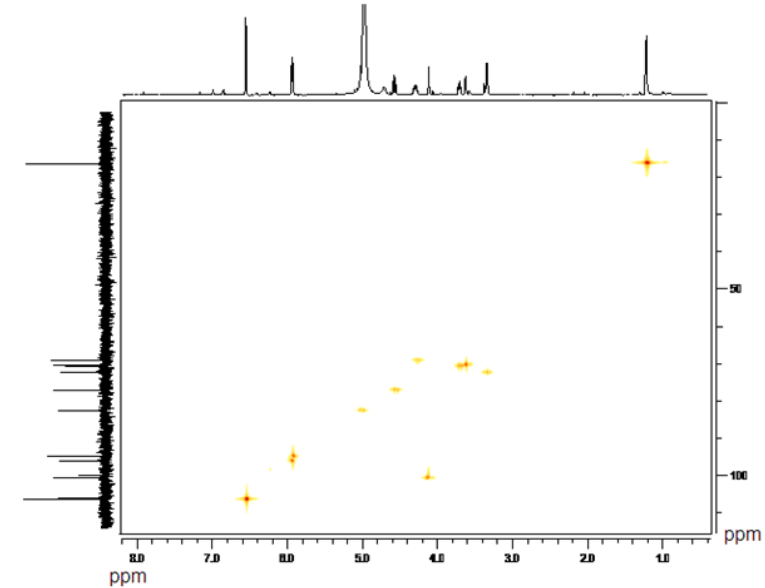


Figure S7. HMBC spectrum of KNA-1.

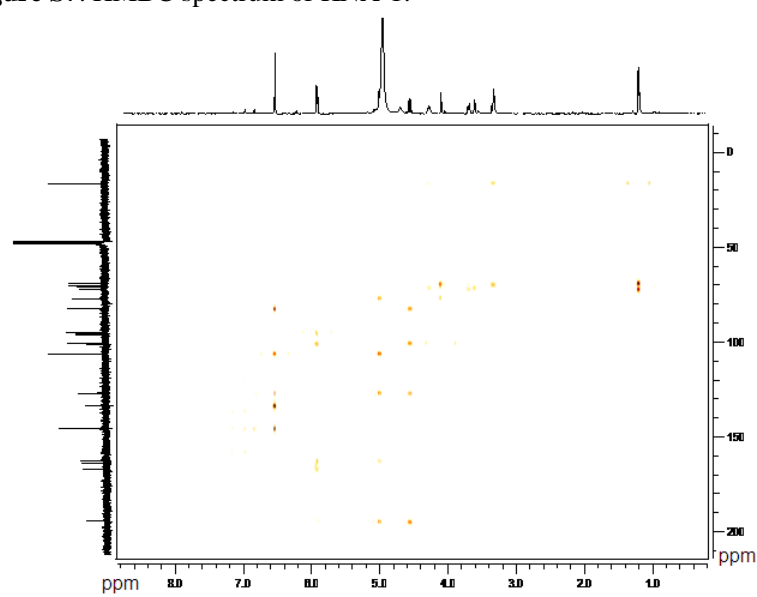

Figure S8. ${ }^{1} \mathrm{H}$ NMR (400 MHz, MeOD) spectrum of KNA-2.

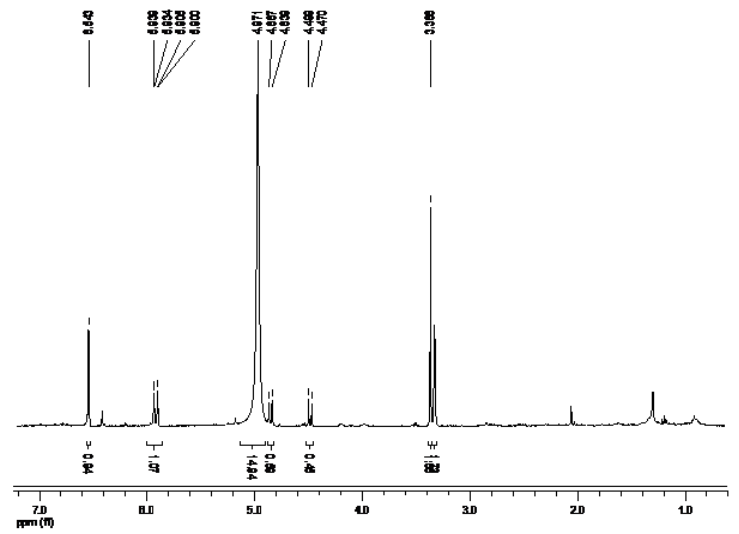

Figure S9. ${ }^{13} \mathrm{C}$ NMR (400 MHz, MeOD) spectrum of KNA-2.

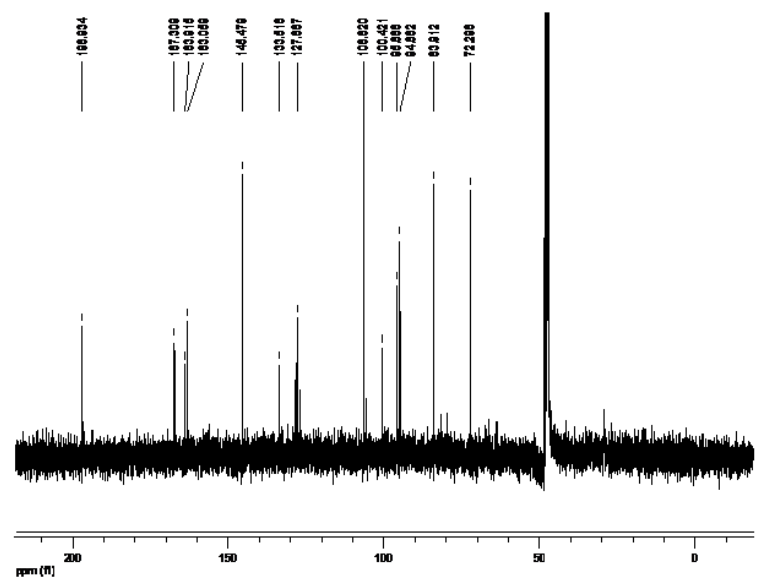

Figure S10. DEPT-135 spectrum of KNA-2.
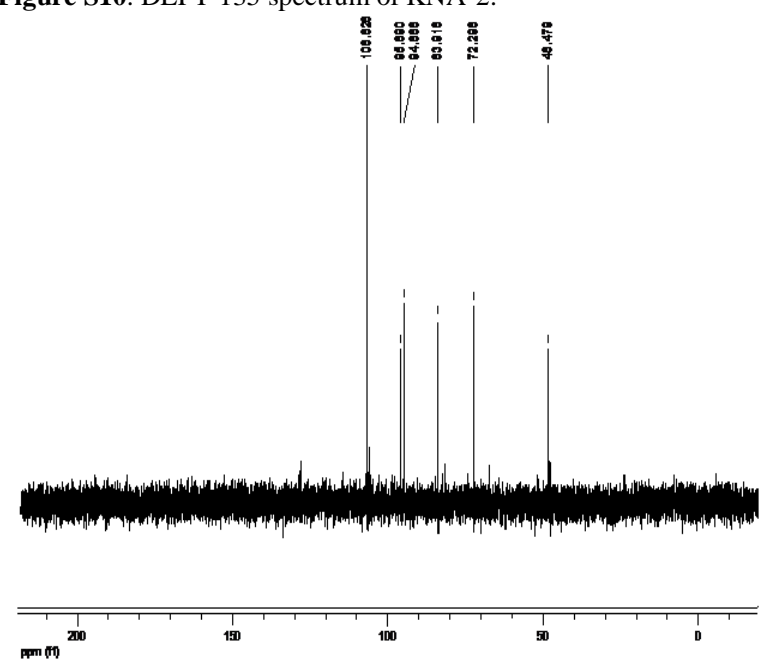
THIS PAGE INTENTIONALLY LEFT BLANK 